\title{
Graduate students navigating social-ecological research: insights from the Long-Term Ecological Research Network
}

\author{
$\underline{\text { Sydne Record }}^{1}, \underline{\text { Paige F. B. Ferguson }}^{2,3}{ }^{9.10} \underline{\text { Elise Benveniste }}^{4}, \underline{\text { Rose A. Graves }}^{5}$, Vera W. Pfeiffer $^{6}{ }^{6} \underline{\text { Michele Romolini }}^{7}$, Christie E. Yorke $^{8}$
} and Ben Beardmore ${ }^{9,10}$

\begin{abstract}
Interdisciplinary, collaborative research capable of capturing the feedbacks between biophysical and social systems can improve the capacity for sustainable environmental decision making. Networks of researchers provide unique opportunities to foster social-ecological inquiry. Although insights into interdisciplinary research have been discussed elsewhere, they rarely address the role of networks and often come from the perspectives of more senior scientists. We have provided graduate student perspectives on interdisciplinary degree paths from within the Long-Term Ecological Research (LTER) Network. Focusing on data from a survey of graduate students in the LTER Network and four self-identified successful graduate student research experiences, we examined the importance of funding, pedagogy, research design and development, communication, networking, and culture and attitude to students pursuing social-ecological research. Through sharing insights from successful graduate student approaches to social-ecological research within the LTER Network, we hope to facilitate dialogue between students, faculty, and networks to improve training for interdisciplinary scientists.
\end{abstract}

Key Words: epistemology; graduate students; Integrated Science for Society and Environment; interdisciplinary; Long-Term Ecological Research Network

\section{INTRODUCTION}

Large-scale and pressing environmental problems, such as climate change, use of water resources, and food security, challenge today's human population (Kinzig 2001). Scientists are being called on to examine these issues, both to better understand the causes and consequences of change and to offer suggestions for policy makers and practitioners (Groffman et al. 2010). Addressing these complex topics requires scientists to ask questions integrating the social and ecological sciences (Ewel 2001, Díaz et al. 2011, Romero and Agrawal 2011, Kueffer et al. 2012). Such research often demands a collaborative team of scientists, including individuals with the ability to integrate across disciplinary and cultural differences (Bammer 2005, Haapasaari et al. 2012, Roy et al. 2013).

The increasing demand for social-ecological research is evident in scientific funding sources, organizations, and networks. Recent solicitations for social-ecological programs from the National Science Foundation (NSF) include the Water Sustainability and Climate program, an area of interest in the Science, Engineering and Education for Sustainability program, and the implementation of the International Network of Research on Coupled Human and Natural Systems (http://chans-net.org). Novel research institutions, such as the U.S. National SocialEnvironmental Synthesis Center and Sweden's Stockholm Resilience Centre, focus specifically on social-ecological research, and networks traditionally focused on ecology have initiatives to incorporate social research (Grimm and Redman 2004, Musacchio and Wu 2004).
We draw on the experiences of graduate student members of one such organization: the NSF-funded Long-Term Ecological Research (LTER) Network. Established in 1980 to encourage ecological research spanning broad temporal and spatial scales (Callahan 1984), the LTER Network is in the implementation phase of a 10-year plan to integrate social and ecological research, the Integrated Science for Society and Environment (ISSE) initiative (U.S. LTER Network 2007, Collins et al. 2011, Robertson et al. 2012). The ISSE initiative defines a socialecological approach as one that "conceptualizes ecosystems as environments driven by complex human and non-human associations, where biophysical and societal elements dynamically and adaptively interact" (U.S. LTER Network 2007:15).

We focus on the experience of graduate students in the LTER Network because, although distributed networks of scholars are prominent in social and/or ecological research, e.g., the Resilience Alliance and the National Ecological Observatory Network, the question of how networks operate has rarely been addressed in the literature. Previous studies on scholarly networks primarily focus on logistical and communication challenges that arise when connecting researchers distributed across sites (Heemskerk et al. 2003, Rhoten and Parker 2004). Focusing on students' experiences in the LTER Network is valuable because each site in the network is focused on a unique social-ecological system, but the sites all operate under common objectives. The sites then can be considered as replicates of an initiative to integrate social and ecological sciences; this makes our results, drawn from multiple sites, more robust. Further, although early career

\footnotetext{
${ }^{1}$ Department of Biology, Bryn Mawr College, ${ }^{2}$ Department of Biological Sciences, University of Alabama, ${ }^{3}$ Warnell School of Forestry and Natural Resources, University of Georgia, ${ }^{4}$ Department of Sociology, Michigan State University, ${ }^{5}$ Department of Zoology, University of WisconsinMadison, ${ }^{6}$ Nelson Institute for Environmental Studies, University of Wisconsin-Madison, ${ }^{7}$ Center for Urban Resilience, Loyola Marymount University, ${ }^{8}$ Interdepartmental Graduate Program in Marine Science, University of California, Santa Barbara, ${ }^{9}$ Center for Limnology, University of Wisconsin-Madison, ${ }^{10}$ Wisconsin Department of Natural Resources
} 
researchers often drive novel directions in network-level science (Graybill and Shandas 2010), few studies address the lived experiences of graduate students within networks (Romolini et al. 2013). We also focus on graduate students because the calls for increased social-ecological scholarship require scientists that are trained to conduct integrative, collaborative, problem-oriented research (Bammer 2005, Sibbel 2009, Lyall and Meagher 2012, Lowe et al. 2013). Although some might reason that socialecological research should be performed by more senior researchers who are already well established (Marini et al. 2011), others support the notion that students, who are future principal investigators, should learn to span disciplines early in their research programs (Golde and Gallagher 1999, Moslemi et al. 2009, Marini et al. 2011).

We provide a complement to Romolini et al. (2013), who described many of the challenges associated with LTER-affiliated socialecological research from a graduate student perspective. In contrast to Romolini et al. (2013), we focus on factors associated with successful graduate student social-ecological research within the LTER Network rather than challenges. Whereas a main objective of Romolini et al. (2013) was to identify some of the barriers associated with performing graduate student socialecological research within the LTER Network across three scales, i.e., individual/project, site, and network scales, a primary objective of ours is to provide advice to students, faculty, and the networks with which they are involved on how to promote graduate student social-ecological research.

Similar to Romolini et al. (2013), we focus on the lived experiences of graduate students within the LTER Network. A comprehensive definition of a social-ecological researcher within the LTER Network has not yet emerged, and training for socialecological researchers can take many, often nonlinear, routes (Romolini et al. 2013). Given the nascence of the field, the mentoring and institutions needed to support this research may not be as defined as in other areas of study, and standards for interdisciplinary degrees may not be well established (Wiek et al. 2011, Cox 2012). Also, approaches to social-ecological research may vary along a continuum from multidisciplinary to transdisciplinary (Miller et al. 2008; Table 1). Because the training of social-ecological researchers is both important and challenging, it is valuable to hear the graduate student perspective to better understand how someone becomes a social-ecological researcher. However, literature on the lived experiences of graduate students engaged in multidisciplinary to transdisciplinary science remains scant (cf. Graybill et al. 2006, Morse et al. 2007, Colón-Rivera et al. 2013, Andrade et al. 2014). Further, a limited number of LTER students consider themselves to have achieved success as social-ecological scholars, and thus, unpacking their experiences will provide a better understanding of the process of becoming a social-ecological researcher within a network.

Our purpose is twofold: (1) to better understand the process of becoming a social-ecological researcher through the eyes of graduate students involved in a national network and (2) to provide advice for students, advisers, and academic networks interested in the training of social-ecological researchers. From examples of graduate student experiences in the LTER Network, we highlight key factors that students identified as contributing to the success of their social-ecological research. Whether research was successful was determined by the student researchers, but successful research can generally be considered that in which the students believed they answered the interdisciplinary questions they set out to address. Insights from LTER graduate students can be useful for several audiences interested in social-ecological research, e.g., potential students, current students, early career scientists, and mentors and networks providing support for graduate research.

Table 1. Students pursuing social-ecological projects have several available research approaches. Whether to pursue a multidisciplinary, interdisciplinary, or transdisciplinary strategy will largely depend on the research questions and systems of study. We follow the definitions of disciplinarity in regard to research described by Miller et al. (2008).

\begin{tabular}{ll}
\hline \hline Disciplinary Term & Definition \\
\hline $\begin{array}{l}\text { Multidisciplinary } \\
\text { research }\end{array}$ & $\begin{array}{l}\text { Research in which individual researchers consider } \\
\text { a common set of issues but maintain disciplinary } \\
\text { boundaries. }\end{array}$ \\
$\begin{array}{l}\text { Interdisciplinary } \\
\text { research }\end{array}$ & $\begin{array}{l}\text { Research characterized by unified problem } \\
\text { formulation, sharing of methods, and perhaps } \\
\text { the creation of new questions. }\end{array}$ \\
$\begin{array}{l}\text { Transdisciplinary } \\
\text { research }\end{array}$ & $\begin{array}{l}\text { Research that transcends entrenched categories } \\
\text { to formulate problems in new ways. }\end{array}$ \\
\hline
\end{tabular}

We eight authors are all current or recent graduates of LTER programs, i.e., less than five years from the receipt of a doctoral degree, and our graduate research spans the spectrum of disciplinary to transdisciplinary in scope. Our insights informed the design and direction of our work, so we do not purport it to be an unbiased representation. Rather, our own experiences contributed to critical evaluation of those we describe.

\section{INSIGHTS FROM THE LONG-TERM ECOLOGICAL RESEARCH NETWORK}

We draw on survey data including all graduate students in the LTER Network and more detailed narrative experiences of four graduate students in the LTER Network to examine socialecological research approaches and to identify six common factors associated with successful graduate student socialecological research. The factors were related to three levels: student; faculty, i.e., adviser and committee members; and network (Fig. 1). At the time we collected the four narratives, three of the projects were still in progress, whereas the last was completed three years prior. We recognize that definitions of success and approaches to social-ecological research, i.e., multidisciplinary and interdisciplinary (Table 1), varied among students. So we consider LTER social-ecological research, as defined by the graduate student researcher, in contrast to disciplinary research, i.e., only ecological or social.

The first data source is a broad online survey that was sent to all students, i.e., 650 graduate and undergraduate students, listed on the LTER Network student Listserv in 2009 (see appendix 1 of Romolini et al. 2013). The survey, consisting of 31 open- and closed-ended questions, was developed by a focus group of 19 graduate students with backgrounds in social, ecological, and social-ecological research from 6 LTER sites. Survey questions covered the following topics: the types of research students were 
performing; institutional and disciplinary affiliations; familiarity with and attitudes toward social-ecological research; and the challenges and opportunities related to doing social-ecological research. The survey was pretested on volunteers. Data were collected from 103 students, and there were 57 fully completed responses.

Fig. 1. Six factors that were identified as key contributors to success in social-ecological research by graduate students: attitude and culture, research development, networking, communication, pedagogical approach, and funding. Within each feature, there are recommendations that students, faculty, and networks might employ to build the capacity for graduate student social-ecological research. RFP, request for proposal. Graphic courtesy of S. Bond.

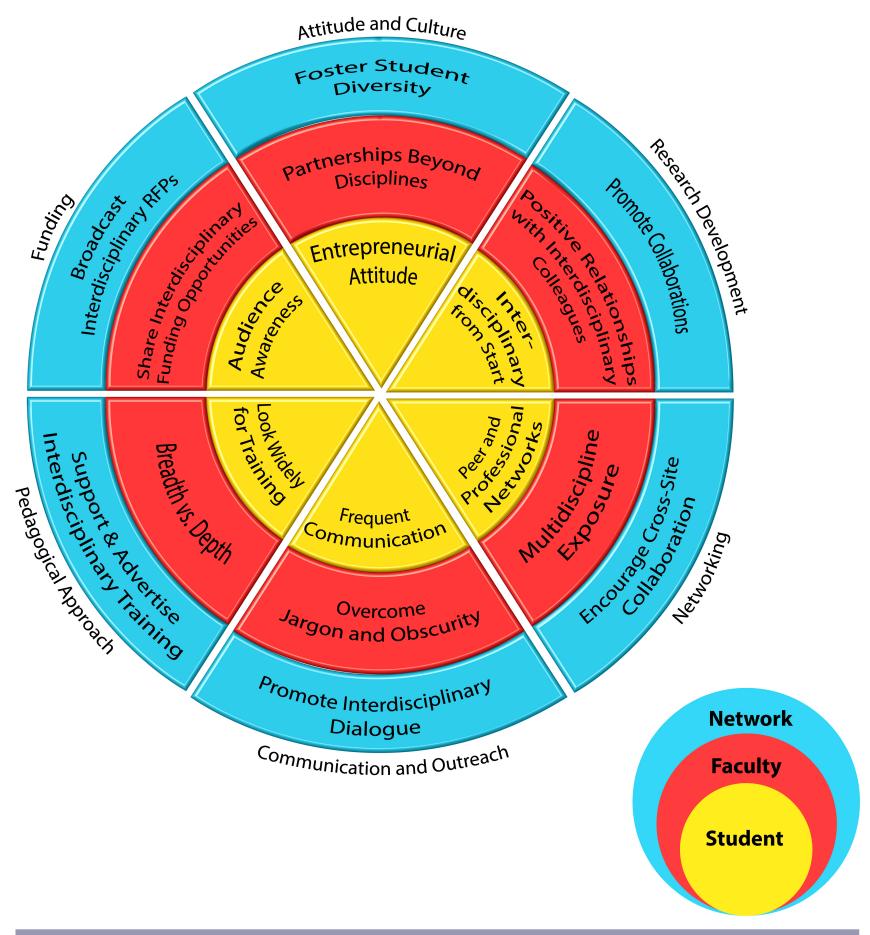

The second data source is composed of narratives from 4 students who self-identified as having done successful social-ecological research as graduate students within the LTER Network. Two of these students were interviewed in 2010 as part of the study by Romolini et al. (2013), which included interviews with some of the survey respondents who self-identified as conducting socialecological research (Table 2). Of the 10 interviews conducted in 2010 , only 2 respondents clearly considered their social-ecological research projects successful (Romolini et al. 2013). Their selfidentification of success is corroborated by their publishing record, as determined from a Web of Science search and publications listed on the researchers' web pages. These 2 interviewees have the greatest number of total publications and publications on social-ecological research out of the 10 interviewees, not considering 1 interviewee who had 1 publication from work with the LTER Network but many subsequent publications. We are not including this researcher's experience because our analysis is investigating factors associated with successful social-ecological research in the LTER Network.
Table 2. Descriptions of social-ecological research projects conducted by graduate students in the Long-Term Ecological Research Network.

\begin{tabular}{cl}
\hline \hline Example & General Research Areas \\
\hline 1 & Population ecology and land use \\
2 & Ecological monitoring and natural resource use \\
3 & Social-ecological attributes of private properties \\
4 & Forest resources \\
\hline
\end{tabular}

The two respondents with successful LTER social-ecological research were part of NSF's Interdisciplinary Graduate Education Research and Training (IGERT) program, so to show a greater diversity in programs, two other students who were not in IGERT programs were identified in 2012. These two students were selected based on the purposive sampling approach in qualitative research (Patton 1990), whereby all narratives must meet certain criteria. Both of these students self-identified as conducting a successful social-ecological graduate research project within the LTER Network. Although these two researchers currently do not have as many publications as other interviewees, this may be because one just finished a degree and the other has a nonacademic job. These two researchers provided written rather than the oral responses, but they addressed questions similar to the semistructured interviews in 2010 used by Romolini et al. (2013), justifying our use of the two types of narratives together. To further differentiate the cultural and institutional context that we examined, each of the four narratives represented a different LTER site. These four narratives were deemed sufficient for illustrative purposes because respondents began reporting similar factors of success after collecting the second round of narratives in 2012. From these four narratives, we identified six factors associated with successful socialecological research by graduate students in the LTER Network.

\section{Funding}

According to the survey data, $35 \%$ of students thought funding was a primary challenge related to social-ecological research. Thirty-eight percent of the students who felt that funding was a difficulty in performing social-ecological research were actually conducting social-ecological research, and $62 \%$ were doing disciplinary research, i.e., purely social or ecological. Of the 12 students who were performing social-ecological research, funding came from the following sources: the NSF, 6 students with 1 student reporting that the money came from NSF via the LTER; the National Atmospheric and Oceanic Administration, 1 student; their university, 6 students; or private foundations, 5 students. Seven of these 12 students received funding from multiple sources ranging from 2 to 3 funders, suggesting that actively seeking funding from a variety of sources is important to funding success.

Students from the narrative data found it necessary to seek out funding opportunities specific to their project. These funding opportunities were difficult to find because funding calls were not always broadcast to eligible applicants. One student based in a biology department mentioned that although funding for the applied ecology aspect of her research was easily obtained, an 
NSF call for proposals to address human aspects within the LTER was only sent to social science Listservs. Fortunately, a committee member from the geography department was able to forward the funding call to her. Had she not established connections within the social sciences faculty, she would have remained unaware of this critical opportunity, suggesting that faculty members can play a key role in broadcasting funding opportunities. This narrative also suggests that the funding benefits of being associated with the LTER Network depend on student awareness of network resources. Romolini et al. (2013) also found that student exposure to the network was highly variable among students, suggesting that the benefits gained by being affiliated with the network need to be more widely broadcasted.

Not only did students find it necessary to network to take advantage of funding opportunities, but they also found it helpful to consider that members of funding committees might not have expertise in some aspects of their project. As one student described it, "There are lots of diverse perspectives on [socialecological research] right now, which I think is a good thing. But it makes it very hard to get it funded because depending on who's reading the proposals, they have a lot of different perspectives on what this actually means." This sentiment echoes those of a working group on the professional development of interdisciplinary environmental scholars organized by the Association for Environmental Studies and Sciences in 2010, suggesting that challenges with diverse sets of reviewers for interdisciplinary proposals are pervasive beyond graduate students in the LTER Network (Clark et al. 2011).

Funding explicitly geared toward social-ecological research was another key factor in student success. Although IGERT played a substantial role for 2 narrative experiences, the LTER Network Office played an important role for a third narrative experience through funding workshops to bring interdisciplinary teams together from different sites. However, when asked in the survey if the LTER Network provided adequate support for socialecological research, the majority (68\%) of students neither agreed nor disagreed. Only $8 \%$ of students agreed that the LTER Network provided adequate support for social-ecological research, whereas $23 \%$ disagreed. The high rate of ambivalence about fiduciary support for social-ecological research by the network suggests that funding opportunities, if available, may have not been well broadcasted. There was student interest in more funding opportunities offered by the LTER Network to support social-ecological research. When asked if they would be interested in a short fellowship in residence at another LTER site to facilitate learning how to carry out a specific social-ecological method or to collect specific data, $52 \%$ of students agreed, $18 \%$ disagreed, and $30 \%$ neither agreed nor disagreed.

\section{Funding recommendations}

- Students: Search widely across disciplines for grants, limit disciplinary jargon in proposals, integrate disciplinary approaches, address current issues of concern, and specifically seek funding from sources known to support social-ecological research.

- Faculty: Keep an eye out for funding opportunities that support social-ecological research to share with interested students.
- Networks: Broadcast social-ecological funding opportunities widely.

\section{Pedagogical approach}

Social-ecological research is often broader in scope, i.e., covering more disparate topics, than disciplinary research (Gilbert 1998, Eigenbrode et al. 2007). Students engaged in social-ecological research therefore require greater flexibility in how they acquire needed expertise. Informal channels play an important role in students' ability to learn the relevant methods and theories from different fields. As one student described it in the narrative, "Being friends with graduate students in different fields helped me a lot."

This narrative also suggested that multidisciplinary course work was critical to exposing students to a broad range of social science and ecological theories and approaches needed for dissertation work, yet only $16 \%$ of the students in the LTER Network had taken a course on social-ecological theory or methods. Seventy percent of students who had taken a social-ecological course had taken it at their home university. When asked if the LTER Network should periodically offer a graduate course on either social-ecological methods or theory, all respondents either disagreed or strongly disagreed, including students who were interested in social-ecological research, i.e., those who had taken social-ecological course work and were performing socialecological research.

This result suggests that students did not perceive the network as an obvious place to seek out social-ecological course work, although the LTER Network has offered such courses. For example, in 2007 and 2008 the LTER Network offered an interdisciplinary course addressing social-ecological methodology, "From Yardstick to Gyroscope," through Arizona State University, the University of Georgia, Florida International University, and the University of Vermont and made available to a broader student body online. Boden et al. (2011) in a study of two universities funded by at least four NSF IGERT awards, each coupling a wide range of disciplines from art to engineering, also found that students tended to look primarily to departments within their institutions for training opportunities.

In addition to thinking more broadly about training opportunities, the demands of multidisciplinary course work require a shift in expectations about the students' disciplinary standards. Successful student narratives spoke of faculty members who valued breadth of knowledge and engaged in interdisciplinary curriculum development, and students felt that these faculty members were more likely to support them in identifying the right balance of specialization. One student summed up this balance of specialization as follows: "You're scratching the surface of four or five different aspects ... each thing that you do will be rigorous ..., but it will not be very deep." The narratives suggest that programs like the NSF's flagship interdisciplinary training program, IGERT, foster this epistemological approach, but continued funding for IGERT is uncertain because the program did not solicit for fiscal years 2013-2015.

\section{Pedagogical recommendations}

- Students: Look widely for training opportunities, both within and outside departments and institutions. 
- Faculty: Be understanding and open about the level of breadth versus depth appropriate to a students' research and training aspirations.

- Networks: When providing interdisciplinary training opportunities, advertise them widely among students to encourage awareness.

\section{Research development}

Including people from multiple disciplines from the beginning facilitated research development according to the student narratives. For instance, one student said, "Rather than just doing ecology and then bringing in the social scientists on the side, create interdisciplinary ideas and methods from the beginning, so that at the end you have a project that is integrated throughout." Students benefited from the expert advice and training of a committee including faculty from multiple disciplines in other ways as well. For example, one student emphasized that "having an anthropologist on my committee ... helped [me] to learn the methods and theories ... and to get through logistics like human subject approval."

Preexisting, trusting relationships among faculty from multiple departments and stakeholders also assisted graduate students. These relationships are so important to project success that when these relationships do not already exist, one student narrative suggested students initiate them by "going out and seeking out [interdisciplinary collaborators]." Institutions can make the structure of departments and requirements for timelines, residency, course work, committee members, and forms of scholarly products supportive for students to develop these relationships as they design their research.

In terms of the perceptions of students toward social-ecological collaborations within the network, the survey found that the majority $(85 \%)$ of graduate students in the LTER Network with either disciplinary or social-ecological research focuses did not feel that collaboration was a barrier to performing socialecological research. In the survey, we defined collaboration as "research that typically involves actively working with other colleagues as part of a larger research team to answer a research question." A higher percentage (92\%) of students performing social-ecological research were performing collaborative research than the percentage of students not performing social-ecological research who were doing collaborative work (58\%). However, these 2 percentages were only marginally significantly different $\left(\chi_{1,60}^{2}=3.34, p=0.068\right)$.

All students in the narratives had collaborators, e.g., advisers, postdocs, or other students, from multiple disciplines, either within their LTER site or across sites. One student felt that a strength of the LTER site was "initiating collaborations across disciplines." Yet another student felt that collaborations across disciplines at the LTER site was primarily because of the enthusiasm of one particular faculty member as opposed to network-level support: "[The faculty member] swung [his/her] whole career in the last 10 years, particularly towards the integration of social sciences ... there are key people, like [blank], who have the ability to make shifts in things."

\section{Research development recommendations}

- Students: Collaborate with people from multiple disciplines from the start of a research project.
- Faculty: Maintain positive relationships with other faculty from multiple disciplines or who are themselves transdisciplinary.

- Networks: Promote collaborations across disciplines to increase student exposure to a wide group of potential collaborators.

\section{Communication}

Good communication skills are an essential part of any graduate program (Fischer and Zigmond 1998), but navigating through shifting expectations as a student refines the balance between the breadth and depth of his or her research especially requires continuous, open communication between the student and faculty advisers. The narrative experiences indicated that for students working on social-ecological research with diverse faculty, regular communication was essential to designing and executing research and building understanding and trust. Faculty at institutions can also support students through activities that bring together diverse academic disciplines to communicate about disciplinary norms. Recognizing that "different disciplines do things differently" and devoting time to reach a common understanding was identified by one student as a key to the success of his or her project.

Prioritizing the communication skills required to translate discipline-specific jargon to broader audiences also played a key role in student success. One student credited the IGERT program for teaching "how to step back and communicate with people from very different points of view ... and how to put aside assumptions and bring them back as necessary." In an evaluation of another IGERT program outside of the LTER Network, Moslemi et al. (2009) described how the Biogeochemistry and Environmental Biocomplexity IGERT at Cornell University supported an interdisciplinary weekly seminar series enabling students to practice their communication skills with researchers from disciplines outside of their interdisciplinary program. In the survey, only $30 \%$ of respondents representing 9 LTER sites indicated that their LTER site brought in speakers to discuss social-ecological research topics. Only 1 of those 9 LTER sites brought in speakers at a frequency greater than every 4 months.

Stable partnerships between LTER sites and communities also facilitated student engagement with stakeholders, something highlighted in a narrative describing recent changes at one LTER site: "Because of the LTER site's historic focus on research in the ... [area] ... nearest the site headquarters, the surrounding community did not know much about what was done [there]. Now LTER PIs and graduate students have created a program to foster dialogue between the site and the community." It is important to note that communication with stakeholders need not just be an important aspect of social-ecological research but can also be relevant to disciplinary research (Duchelle et al. 2009). Further, strong interpersonal skills influence communication and are important for working in collaborative teams doing either disciplinary or interdisciplinary research (Cheruvelil et al. 2014).

\section{Communication recommendations}

- Students: Maintain frequent communication with faculty and, when applicable, stakeholders to be better able to design and execute successful research projects in which all parties involved benefit. 
- Faculty: Teach how to avoid discipline-specific jargon to help students convey their research to broader audiences.

- Networks: Facilitate training of students in interdisciplinary communication skills by holding interdisciplinary seminars and promote dialogue with stakeholders by maintaining relationships with community members beyond sites.

\section{Networking}

The narratives indicated that graduate students found support in both peer and professional networks. Participating in groups like IGERT helped students learn how to collaborate with colleagues from different disciplines. Students at one university formed their own program, modeled after IGERT, for graduate students who combined social and ecological research. Although all such programs are not the same, this finding echoes previous research that rigorously evaluated the IGERT program (Morse et al. 2007, August et al. 2010) and suggests that NSF ought to reconsider the continuation of IGERT awards or that universities and/or networks, like the LTER Network, might model social-ecological initiatives after relevant IGERT programs.

Faculty members who make students aware of interdisciplinary networks and encourage the formation of multidisciplinary committees also support student networking. One student described in a narrative being encouraged by a primary adviser to form a multidisciplinary committee of members from multiple LTER sites to perform a cross-site study. The student felt that collaborating with these committee members from multiple LTER sites was "very practical; we all [learned] a lot from each other."

Exposure to researchers across sites is a unique way that networks like the LTER Network promote cross dialogue among researchers, both within and among disciplines. This type of networking, if centralized around an initiative such as the ISSE, could help to facilitate communities of practice for socialecological research that may not be fostered as much in disciplinary departments within universities. For example, we authors, who represent six LTER sites and range the full spectrum from ecologists to transdisciplinary social ecologists, began collaborating at a working group at the 2012 LTER Network's All Scientists Meeting.

The survey data, however, indicated that cross-site collaborations were not pervasive among graduate students, with only $3 \%$ of students being actively involved in research (equal numbers of disciplinary vs. social-ecological projects) spanning multiple sites. Despite a low level of cross-site collaboration among graduate students, $62 \%$ of respondents were interested in the potential of having the LTER Network offer a summer workshop that would expose them to social-ecological research at other LTER sites.

\section{Networking recommendations}

- Students: Actively seek out social-ecological peer and professional networks.

- Faculty: Bring students' attention to potentially relevant advisers and resources for social-ecological research within the LTER Network.

- Networks: Encourage cross-site social-ecological collaborations through meetings and workshops.

\section{Attitude and culture}

From the narratives, we found that students engaged in socialecological research often had an entrepreneurial attitude that was manifested through their search for funding, not being bound by disciplinary stereotypes, and cultural sensitivity to the values and perspectives of stakeholders. In a case in which one student's adviser warned her that stakeholders would not welcome her intrusion on their properties to collect field data, by emphasizing communication and collaboration, she found them to be "overwhelmingly supportive and friendly." Flexibility and good communication were invaluable skills for completing course work requirements, working with faculty from multiple departments, and engaging with stakeholders in applied projects. For instance, one student credited her ability to complete her dissertation to "confidence in [her] own work, commitment to working with the ... community and various faculty, and persistence when faced with challenges." The narratives also suggested that students interested in social-ecological research ought to think carefully about program choice, for as one respondent put it, students want to be at an institution "where [a student's] lack of experience in a discipline is not necessarily seen as a shortcoming but is seen as an opportunity for [a student] to learn." Explicitly interdisciplinary graduate programs may be more likely than disciplinary programs to encourage open dialogue across disciplines and to foster a peer support network that extends beyond the student's home department.

Faculty contributed to a supportive culture by recognizing differences in disciplinary standards and demonstrating a willingness to partner across disciplines to meet students' needs. As one student said about her adviser, "If there is a sociologist who wants to participate, they [sic] won't be excluded." Survey results showed that $12 \%$ of students not performing socialecological research in the LTER Network felt that adviser support was a significant challenge to performing graduate student socialecological research, whereas $33 \%$ of students performing socialecological research in the LTER Network felt that adviser support was a challenge. These results suggest that advisers of students performing social-ecological research within the LTER Network should be especially aware of providing adequate support for their students.

Many of the insights from previous sections highlight ways in which the LTER Network might foster a culture conducive to graduate student social-ecological research. Within the narratives, there was one way in which institutions contributed to a culture of fostering social-ecological student research that could extend to the LTER Network: fostering diversity via the acceptance of graduate students from traditionally underrepresented backgrounds. Departments in which there were "very few people who shut down students from different backgrounds if they [wanted] to contribute" and in which students from different disciplinary backgrounds were "not going to be treated like an idiot in this class" were credited by a student for their interdisciplinary success. Cheruvelil et al. (2014) also found that promoting diversity, broadly defined, built cultures amenable to collaborative research.

\section{Attitude and culture recommendations}

- Students: Approach research with an entrepreneurial attitude. 
- Faculty: Acknowledge disciplinary standards and, if your research is disciplinary, be willing to partner with colleagues from other disciplines or transdisciplinary colleagues to support students.

- Networks: Foster student diversity.

\section{CONCLUSIONS}

There is unprecedented opportunity for social-ecological research to benefit society by helping to inform decisions about pressing environmental problems (Kinzig 2001, Groffmann et al. 2010, Whitmer et al. 2010). Many social-ecological research projects are suited for engaging stakeholders with the potential to span the divide between academic research and the general public, increasing the relevance of research findings to environmental decision making (Overdevest et al. 2004, Pace et al. 2010). Given the potential for social-ecological research to occur within networks of distributed researchers, such as the LTER Network and the Resilience Alliance, it is important to understand how networks can help to promote social-ecological projects and training.

Training social-ecological researchers within distributed research networks to perform transformative studies presents a number of unique challenges that are not typically encountered in a traditional, disciplinary graduate program (Bammer 2005, Romolini et al. 2013). Therefore, it is important to encourage dialogue about what factors lead to training of students to perform successful social-ecological research (Roy et al. 2013). Considering the experiences of graduate students who conducted successful social-ecological research through many sites in the LTER Network provided a powerful new way to identify key factors leading to successful research. The insights we present into the multiple drivers contributing to the success of graduate student social-ecological research in the LTER Network provide a unique perspective into the lived experiences of graduate students.

Although some factors were more greatly discussed in a subset of the narratives, communication and attitude and culture were emphasized by all. This finding suggests that there is potential for students, advisers, and networks to open communication, create a collaborative culture, and foster entrepreneurial attitudes to increase the likelihood of successful graduate training and research. Further, although communication and attitude and culture were emphasized by all respondents, many of these factors overlap; for example, good communication skills often facilitate networking. Increased dialogue among students, faculty, and networks will benefit the training of social-ecological researchers and result in research findings that inform pertinent environmental decisions.

Responses to this article can be read online at: http://www.ecologyandsociety.org/issues/responses. $\mathrm{php} / 8111$

\section{Acknowledgments:}

The authors developed the paper from a working group at the 2012 LTER All Scientists Meeting and received funding from the
National Science Foundation via the LTER Network. C. Beier, S. Carpenter, E. Cook, C. Guenther, N. Heynin, B. Provencher, C. Semeniuk, and two anonymous reviewers provided useful comments on the manuscript. S. Bond illustrated the figures. This study follows best practices of the Institutional Review Board (IRB number CHRBS: B10-184).

\section{LITERATURE CITED}

Andrade, K., C. Corbin, S. Diver, M. V. Eitzel, J. Williamson, J. Brashares, and L. Fortmann. 2014. Finding your way in the interdisciplinary forest: notes on educating future conservation practitioners. Biodiversity and Conservation 23:3405-3423. http:// dx.doi.org/10.1007/s10531-014-0818-z

August, P. V., J. M. Swift, D. Q. Kellogg, G. Page, P. Nelson, J. Opaluch, J. S. Cobb, C. Foster, and A. J. Gold. 2010. The T assessment tool: a simple metric for assessing multidisciplinary graduate education. Journal of Natural Resources and Life Sciences Education 39:15-21. http://dx.doi.org/10.4195/jnrlse.2009.0004

Bammer, G. 2005. Integration and implementation sciences: building a new specialization. Ecology and Society 10(2):6. [online] URL: http://www.ecologyandsociety.org/vol10/iss 2/ art6/

Boden, D., M. Borrego, and L. K. Newswander. 2011. Student socialization in interdisciplinary doctoral education. Higher Education 62:741-755. http://dx.doi.org/10.1007/s10734-011-9415-1

Callahan, J. T. 1984. Long term ecological research. BioScience 34:363-367. http://dx.doi.org/10.2307/1309727

Cheruvelil, K. S., P. A. Soranno, K. C. Weathers, P. C. Hanson, S. J. Goring, C. T. Filstrup, and E. K. Read. 2014. Creating and maintaining high-performing collaborative research teams: the importance of diversity and interpersonal skills. Frontiers in Ecology and the Environment 12:31-38. http://dx.doi. org/10.1890/130001

Clark, S. G., M. M. Steen-Adams, S. Pfirman, and R. L. Wallace. 2011. Professional development of interdisciplinary environmental scholars. Journal of Environmental Studies and Sciences 1:99-113. http://dx.doi.org/10.1007/s13412-011-0018-z

Collins, S. L., S. R. Carpenter, S. M. Swinton, D. E. Orenstein, D. L. Childers, T. L. Gragson, N. B. Grimm, J. M. Grove, S. L. Harlan, J. P. Kaye, A. K. Knapp, G. P. Kofinas, J. J. Magnuson, W. H. McDowell, J. M. Melack, L. A. Ogden, G. P. Robertson, M. D. Smith, and A. C. Whitmer. 2011. An integrated conceptual framework for long-term social-ecological research. Frontiers in Ecology and the Environment 9:351-357. http://dx.doi. org/10.1890/100068

Colón-Rivera, R. J., K. Marshall, F. J. Soto-Santiago, D. OrtizTorres, and C. E. Flower. 2013. Moving forward: fostering the next generation of Earth stewards in the STEM disciplines. Frontiers in Ecology and the Environment 11:383-391. http://dx. doi.org/10.1890/120307

Cox, M. 2012. Diagnosing institutional fit: a formal perspective. Ecology and Society 17(4):54. http://dx.doi.org/10.5751/ es-05173-170454 
Díaz, S., F. Quétier, M. Cáceres, S. F. Trainor, N. PérezHarguindeguy, M. S. Bret-Harte, B. Finegan, M. Peña-Claros, and L. Poorter. 2011. Linking functional diversity and social actor strategies in a framework for interdisciplinary analysis of nature's benefits to society. Proceedings of the National Academy of Sciences of the United States of America 108:895-902. http://dx. doi.org/10.1073/pnas.1017993108

Duchelle, A. E., K. Biedenweg, C. Lucas, A. Virapongse, J. Radachowsky, D. J. Wojcik, M. Londres, W.-L. Bartels, D. Alvira, and K. A. Kalner. 2009. Graduate students and knowledge exchange with local stakeholders: possibilities and preparation. Biotropica 41:578-585. http://dx.doi.org/10.1111/j.1744-7429.2009.00563. $\underline{\mathrm{x}}$

Eigenbrode, S. D., M. O'Rourke, J. D. Wulfhorst, D. M. Althoff, C. S. Goldberg, K. Merrill, W. Morse, M. Nielsen-Pincus, J. Stephens, L. Winowiecki, and N. A. Bosque-Pérez. 2007. Employing philosophical dialogue in collaborative science. BioScience 57:55-64. http://dx.doi.org/10.1641/B570109

Ewel, K. C. 2001. Natural resource management: the need for interdisciplinary collaborations. Ecosystems 4:716-722. http://dx. doi.org/10.1007/s10021-001-0040-1

Fischer, B. A., and M. J. Zigmond. 1998. Survival skills for graduate school and beyond. New Directions for Higher Education 1998(101):29-40. http://dx.doi.org/10.1002/he.10103

Gilbert, L. E. 1998. Disciplinary breadth and interdisciplinary knowledge production. Knowledge, Technology and Policy 11:4-15. http://dx.doi.org/10.1007/s12130-998-1007-8

Golde, C. M., and H. A. Gallagher. 1999. The challenges of conducting interdisciplinary research in traditional doctoral programs. Ecosystems 2:281-285. http://dx.doi.org/10.1007/ $\underline{\mathrm{s} 100219900076}$

Graybill, J. K., S. Dooling, V. Shandas, J. Withey, A. Greve, and G. L. Simon. 2006. A rough guide to interdisciplinarity: graduate student perspectives. BioScience 56:757-763. http://dx.doi. org/10.1641/0006-3568(2006)56[757:ARGTIG]2.0.CO;2

Graybill, J. K., and V. Shandas. 2010. Doctoral student and early academic career perspectives on interdisciplinarity. Pages 404-418 in R. Frodeman, R. T. Klein, and C. Mitcham, editors. The Oxford handbook on interdisciplinarity. Oxford University Press, Oxford, UK.

Grimm, N. B., and C. L. Redman. 2004. Approaches to the study of urban ecosystems: the case of Central Arizona-Phoenix. Urban Ecosystems 7:199-213. http://dx.doi.org/10.1023/B: UECO.0000044036.59953.a1

Groffman, P. M., C. Stylinski, N. C. Nisbet, C. M. Duarte, R. Jordan, A. Burgin, M. A. Previtali, and J. Coloso. 2010. Restarting the conversation: challenges at the interface between ecology and society. Frontiers in Ecology and the Environment 8:284-291. http:// dx.doi.org/10.1890/090160

Haapasaari, P., S. Kulmala, and S. Kuikka. 2012. Growing into interdisciplinarity: how to converge biology, economics, and social science in fisheries research? Ecology and Society 17(1):6. http://dx.doi.org/10.5751/es-04503-170106
Heemskerk, M., K. Wilson, and M. Pavao-Zuckerman. 2003. Conceptual models as tools for communication across disciplines. Conservation Ecology 7(3):8. [online] URL: http://www.consecol. org/vol7/iss3/art8/

Kinzig, A. P. 2001. Bridging disciplinary divides to address environmental and intellectual challenges. Ecosystems 4:709-715. http://dx.doi.org/10.1007/s10021-001-0039-7

Kueffer, C., E. Underwood, G. H. Hadorn, R. Holderegger, M. Lehning, C. Pohl, M. Schirmer, R. Schwarzenbach, M. Stauffacher, G. Wuelser, and P. Edwards. 2012. Enabling effective problem-oriented research for sustainable development. Ecology and Society 17(4):8. http://dx.doi.org/10.5751/es-05045-170408

Lowe, P., J. Phillipson, and K. Wilkinson. 2013. Why social scientists should engage with natural scientists. Contemporary Social Science 8:207-222. http://dx.doi.org/10.1080/21582041.2013.769617

Lyall, C., and L. R. Meagher. 2012. A masterclass in interdisciplinarity: research into practice in training the next generation of interdisciplinary researchers. Futures 44:608-617. http://dx.doi.org/10.1016/j.futures.2012.03.011

Marini, A., H. Asbjornsen, L. A. Baker, N. Brozovic, L. E. Drinkwater, S. A. Drzyzga, C. A. Jantz, J. Fragoso, D. S. Holland, T. A. Kohler, J. Liu, W. J. McConnell, H. D. G. Maschner, J. D. A. Millington, M. Monticino, G. Podestá, R. G. Pontius Jr., C. L. Redman, N. J. Reo, D. Sailor, and G. Urquhart. 2011. Research on coupled human and natural systems (CHANS): approaches, challenges, and strategies. Bulletin of the Ecological Society of America 92:218-228. http://dx.doi.org/10.1890/0012-9623-92.2.218

Miller, T. R., T. D. Baird, C. M. Littlefield, G. Kofinas, F. S. Chapin III, and C. L. Redman. 2008. Epistemological pluralism: reorganizing interdisciplinary research. Ecology and Society 13 (2):46. [online] URL: http://www.ecologyandsociety.org/vol13/ iss $2 / \operatorname{art} 46 /$

Morse, W. C., M. Nielsen-Pincus, J. Force, and J. Wulfhorst. 2007. Bridges and barriers to developing and conducting interdisciplinary graduate-student team research. Ecology and Society 12(2):8. [online] URL: http://www.ecologyandsociety. org/vol12/iss $2 / \operatorname{art} 8 /$

Moslemi, J. M., K. A. Capps, M. S. Johnson, J. Maul, P. B. McIntyre, A. M. Melvin, T. M. Vadas, D. M. Vallano, J. M. Watkins, and M. Weiss. 2009. Training tomorrow's environmental problem solvers: an integrative approach to graduate education. BioScience 59:514-521. http://dx.doi.org/10.1525/bio.2009.59.6.10

Musacchio, L. R., and J. Wu. 2004. Collaborative landscape-scale ecological research: emerging trends in urban and regional ecology. Urban Ecosystems 7:175-178. http://dx.doi.org/10.1023/ B:UECO.0000044034.55695.bd

Overdevest, C., C. Huyck Orr, and K. Stepenuck. 2004. Volunteer stream monitoring and local participation in natural resource issues. Human Ecology Review 11:177-185

Pace, M. L., S. E. Hampton, K. E. Limburg, E. M. Bennett, E. M. Cook, A. E. Davis, J. M. Grove, K. Y. Kaneshiro, S. L. LaDeau, G. E. Likens, D. M. McKnight, D. C. Richardson, and D. L. Strayer. 2010. Communicating with the public: opportunities and 
rewards for individual ecologists. Frontiers in Ecology and the Environment 8:292-298. http://dx.doi.org/10.1890/090168

Patton, M. Z. 1990. Qualitative evaluation and research methods. Second edition. Sage, Newbury Park, California, USA.

Rhoten, D., and A. Parker. 2004. Risks and rewards of an interdisciplinary research path. Science 306:2046.

Robertson, G. P., S. L. Collins, D. R. Foster, N. Brokaw, H. W. Ducklow, T. L. Gragson, C. Gries, S. K. Hamilton, A. D. McGuire, J. C. Moore, E. H. Stanley, R. B. Waide, and M. W. Williams. 2012. Long-term ecological research in a humandominated world. BioScience 62:342-353. http://dx.doi. org/10.1525/bio.2012.62.4.6

Romero, C., and A. Agrawal. 2011. Building interdisciplinary frameworks: the importance of institutions, scale, and politics. Proceedings of the National Academy of Sciences of the United States of America 108:E196. http://dx.doi.org/10.1073/ pnas. 1104320108

Romolini, M., S. Record, R. Garvoille, Y. Marusenko, and R. S. Geiger. 2013. The next generation of scientists: examining the experiences of graduate students in network-level socialecological science. Ecology and Society 18(3):42. http://dx.doi. org/10.5751/es-05606-180342

Roy, E. D., A. T. Morzillo, F. Seijo, S. M. W. Reddy, J. M. Rhemtulla, J. C. Milder, T. Kuemmerle, and S. L. Martin. 2013. The elusive pursuit of interdisciplinarity at the humanenvironment interface. BioScience 63:745-753. http://dx.doi. org/10.1093/bioscience/63.9.745

Sibbel, A. 2009. Pathways towards sustainability through higher education. International Journal of Sustainability in Higher Education 10:68-82. http://dx.doi.org/10.1108/14676370910925262

U.S. Long-Term Ecological Research (LTER) Network. 2007. The decadal plan for LTER: integrative science for society and the environment. LTER Network Office Publication Series, No. 24. LTER Network Office, Albuquerque, New Mexico, USA. [online] URL: http://intranet2.1ternet.edu/sites/intranet2.1ternet.edu/files/ documents/Scientific_Reports/Network_Office_Numbered_Publications/ TheDecadalPlanReformattedForBook with citation.pdf

Whitmer, A., L. Ogden, J. Lawton, P. Sturner, P. M. Groffman, L. Schneider, D. Hart, B. Halpern, W. Schlesinger, S. Raciti, N. Bettez, S. Ortega, L. Rustad, S. T. A. Pickett, and M. Killilea. 2010. The engaged university: providing a platform for research that transforms society. Frontiers in Ecology and the Environment 8:314-321. http://dx.doi.org/10.1890/090241

Wiek, A., L. Withycombe, and C. L. Redman. 2011. Key competencies in sustainability: a reference framework for academic program development. Sustainability Science 6:203-218. http://dx.doi.org/10.1007/s11625-011-0132-6 